\title{
New storage facility at Southern Illinois University
}

\author{
By Kenneth G. Peterson \\ Dean of Library Affairs \\ Southern Illinois University at Carbondale
}

\section{A storage site relieves overcrowding at SIU.}

ompletion of a new Library Storage Building at Southern Illinois University in Carbondale has added shelving capacity for approximately 1.5 million volumes and volume equivalents of non-book materials, and is providing relief for serious stack crowding which had developed in Morris Library over the past twenty years.

Morris Library, the university's central library facility, was constructed in two stages. The initial stage, consisting of a basement and two aboveground floors, was opened in January 1956. Five additional levels were added in 1964, and were finished one floor at a time over the next several years. When completed, the building contained 211,417 net assignable square feet, and had been planned to accommodate a collection of one million volumes and an enrollment of approximately 15,000 students. The collection, however, reached the one million volume level in 1967, about the same time the enrollment passed 20,000 students.

Plans for a major addition to Morris Library were drawn in 1969, based upon doubling the building's size, providing a stack tower, and accommodating altogether approximately three million volumes. These plans were approved and appropriations for construction sought from the state legislature in the spring of 1970 . Within a few weeks, however, reactions to the war in Vietnam and the tragedy at Kent State University caused student unrest on the Carbondale campus to erupt into violent confrontations. As a result the university closed before the completion of the spring semester and remained closed until the following fall. This situation brought an angry response from the legislature, and appropriations for the library addition failed to receive approval.

During the decade of the 1970s the library's space problems became increasingly serious. Yearby-year additional ranges of stacks were installed at the expense of space for readers. In 1977 the library conducted a Special Analytical Study that not only described the seriousness of the space problem, but also forecast that a crisis was looming only a few years ahead. The information provided by this study persuaded the university president to authorize the appointment of a Library Building and Planning Committee, charged to consider various options for solving the library's problems and to present recommendations. Unfortunately, when the committee completed its assignment and presented its report in July 1979, the university was searching for a new president and the recommendations were laid aside until the next administration was in place.

Shortly after taking office in late summer of 1980 , the new president acknowledged the library's needs. He also indicated two serious problems-the lack of sufficient capacity in the university's steam plant to accommodate another major building on the campus, and the indication from 


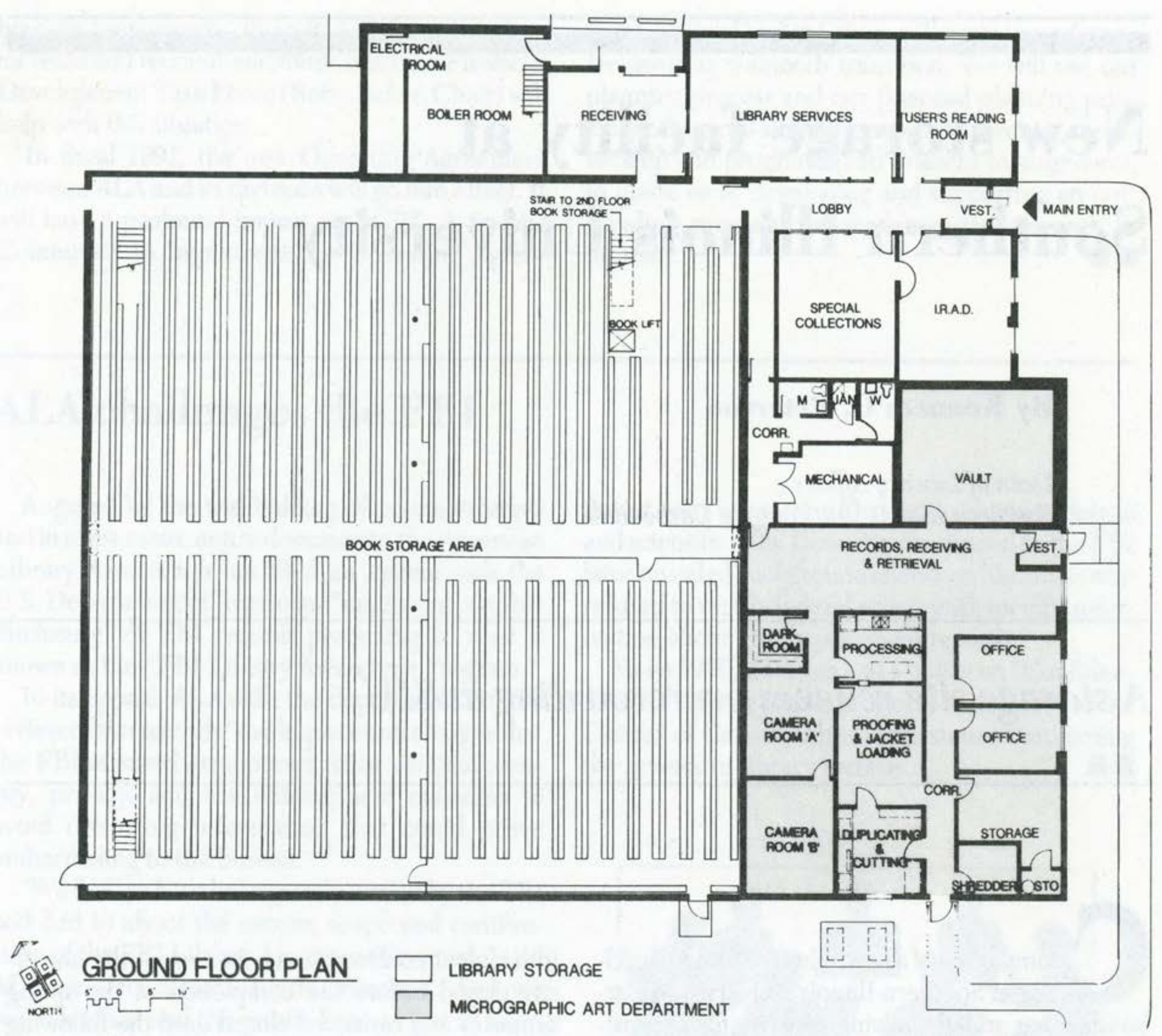

high ranking state officials that funds would probably not be recommended for the new library addition at Carbondale. Therefore, alternative solutions for the library were to be sought. At the president's request a range of options was proposed by the library administration. The one which was generally regarded as most likely to receive support was a library storage building.

Although the library administration strongly favored construction of a new facility, the university administration decided to explore the possibilities of obtaining an existing building in Carbondale or the surrounding region. While several available structures were being considered, a ground swell of opposition arose from faculty and students. In their opinion, if the library had to resort to storing books outside the main building, a facility for this purpose should be constructed on campus where relatively easy access could be assured. Local legislators were persuaded by this argument and introduced amended legislation to provide $\$ 1.6$ million to erect an on-campus library storage building. The appropriation was passed in June 1985, and a site about one mile from the main library, and adjacent to the University Press building, was selected for construction.
During the following fall six architectural firms were invited to make presentations, which resulted in the selection of Fischer/Stein Associates of Carbondale for the project. Meanwhile, a Library Storage Building Planning Committee had been at work gathering information, examining plans of storage buildings at other universities, and writing a program report with recommendations. It was agreed that the new facility should house roughly 500,000 volumes or volume equivalents of nonbook materials, plus facilities to accommodate readers. In addition, work rooms for Library Services, Special Collections, and the Illinois Regional Archives Depository were needed. A shippingreceiving room with loading area, and lavatory facilities were also to be included. Because additional space to accommodate the campus Micrographic Center was being sought at this time, the university administration decided that a portion of the Library Storage Building should be set aside to accommodate this unit with the understanding that, if another facility for micrographics was built or provided at some future time, this space would revert to library use.

Plans for the storage building were completed in the spring of 1986, and bids for construction were 
sought. Based upon the architect's preliminary cost estimates, there was concern that bids might exceed the $\$ 1.6$ million available. Thus, contingency plans were developed which, if necessary, would provide stacks for 100,000 volumes with additional stacks added year-by-year. Fortunately, however, the bids were lower than the appropriation, and contracts were approved for both construction and complete stack installation. Total contract awards were $\$ 1,398,311$-including $\$ 943,700$ for the general contractor (including $\$ 433,156$ for stacks), $\$ 159,473$ for electrical, $\$ 114,000$ for heating, $\$ 93,910$ for plumbing, and $\$ 87,228$ for ventilation. Final costs, including architect fees, site preparation and miscellaneous items, amounted to $\$ 1,622,500$, or $\$ 45.88$ per square foot. The proportionate costs for storing library materials came to 87 cents per volume for stack shelving only, and \$2.84 per volume for stack shelving and storage area (excluding work rooms and micrographics).

The building is a pre-engineered metal structure erected on a concrete slab foundation, and contains a gross area of 32,035 square feet, of which 28,169 is net assignable. Through calculations developed by the architects using a computer program it was determined that the most suitable and cost efficient configuration would be achieved by using stationary shelves on two self-supporting stack levels, and including three stairways and one elevator large enough to accommodate two standard size book trucks. According to the computer analysis this configuration cost roughly $\$ 250,000$ less than one providing comparable capacity but using movable shelves.

Approximately $75 \%$ of the stacks consist of shelves seven inches deep, and the remaining $25 \%$ include both eleven and twelve inch shelves for archival materials and oversize books. Fluorescent tube fixtures provide light and are controlled by local area, as well as zonal area, switches. The building is equipped with a sprinkler system which is zone activated. There are also fire alarms and a movement sensing security system, both of which sound alarms on site as well as at the campus security office. The heating and air conditioning system allows for the stack area to be kept at lower temperatures than the public and work areas of the building. Of the total area, 23,320 square feet accounts for storage of library materials, about 3,872 for the Micrographics Center, and the remainder for office space and the small reading room which can accommodate eight people. Total stack shelving includes 65,983 linear feet.

Twenty-five percent of the stack area (part of which is enclosed with security screening) has been assigned to the library's Special Collections unit and is being used to house the University archives, the Illinois Regional Archives Depository (IRAD), a number of manuscript collections, the archival copies of university theses and dissertations and a collection of older phonorecords. The remaining $75 \%$ of stack shelving is being used for general library materials which are in relatively little demand. Approximately two-thirds of these materials are back runs of bound periodicals and journals, and the remaining one-third are monographs.

The original plan for transferring materials recommended moving one hundred thousand volumes the first year and fifty thousand each year thereafter until capacity was reached. The need to relieve stack crowding and shift collections in Morris Library, along with the availability of additional student help and university trucks, resulted instead in moving more materials initially so that by the end of the first year of use the Library Storage Building was filled to more than sixty percent of capacity. Respecting the strong preferences of both the library staff and the faculty to shelve classified materials by call number and bound serials in alphabetical order, it was decided early in the planning stages not to shelve by size or random order. Although this decision has sacrificed some economies of space, it has gained the support and good will of users accustomed to the amenities of an open-stack main library, who wish occasionally to consult collections directly. It also has eliminated the labor-intensive process of changing bibliographic records and of adding special markings to volumes transferred to storage. Because the library's catalog records have been retrospectively converted to machine-readable form, the database for the online catalog indicates the location of materials which have been transferred to storage.

When faculty support for the storage plan was being sought, the need for accessibility of materials was a primary concern. Thus, the library has established procedures to retrieve requested items twice a day, Mondays through Fridays, charging them out using the circulation system at Morris Library. Users who want to use large quantities of materials may make arrangements to consult or use them at the storage building's reading room, where copying facilities are available. The storage building is staffed by one full-time Library Technical Assistant, plus students who work on part-time schedules. In addition, the Special Collections unit has three graduate assistants each working twenty hours per week to service the IRAD collection. Depending upon both user needs and tasks to be performed, additional staff members from Morris Library and Special Collections may be assigned to work there also. Aside from budgeting funds for student wages, other operating costs at the storage building have been absorbed to date within the budgets of appropriate library departments or divisions.

Both the Library Storage Building and the storage program have proven to be very satisfactory, as 


\section{$\mathrm{MOHAWK}$ M IDLA ND Manufacturers of Quality Library Furniture}

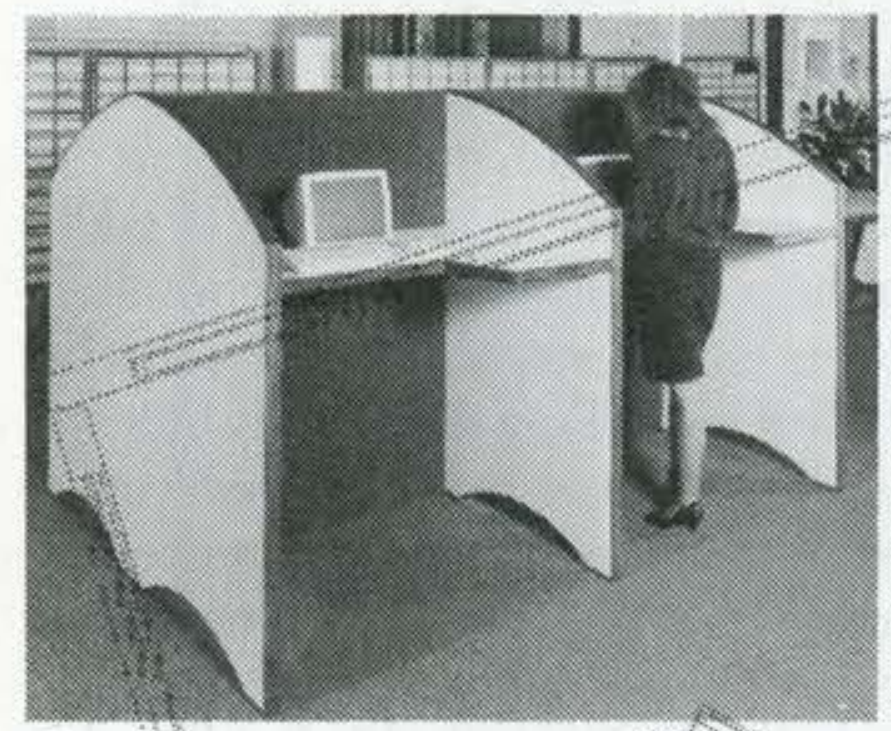

Carrels for automation 1
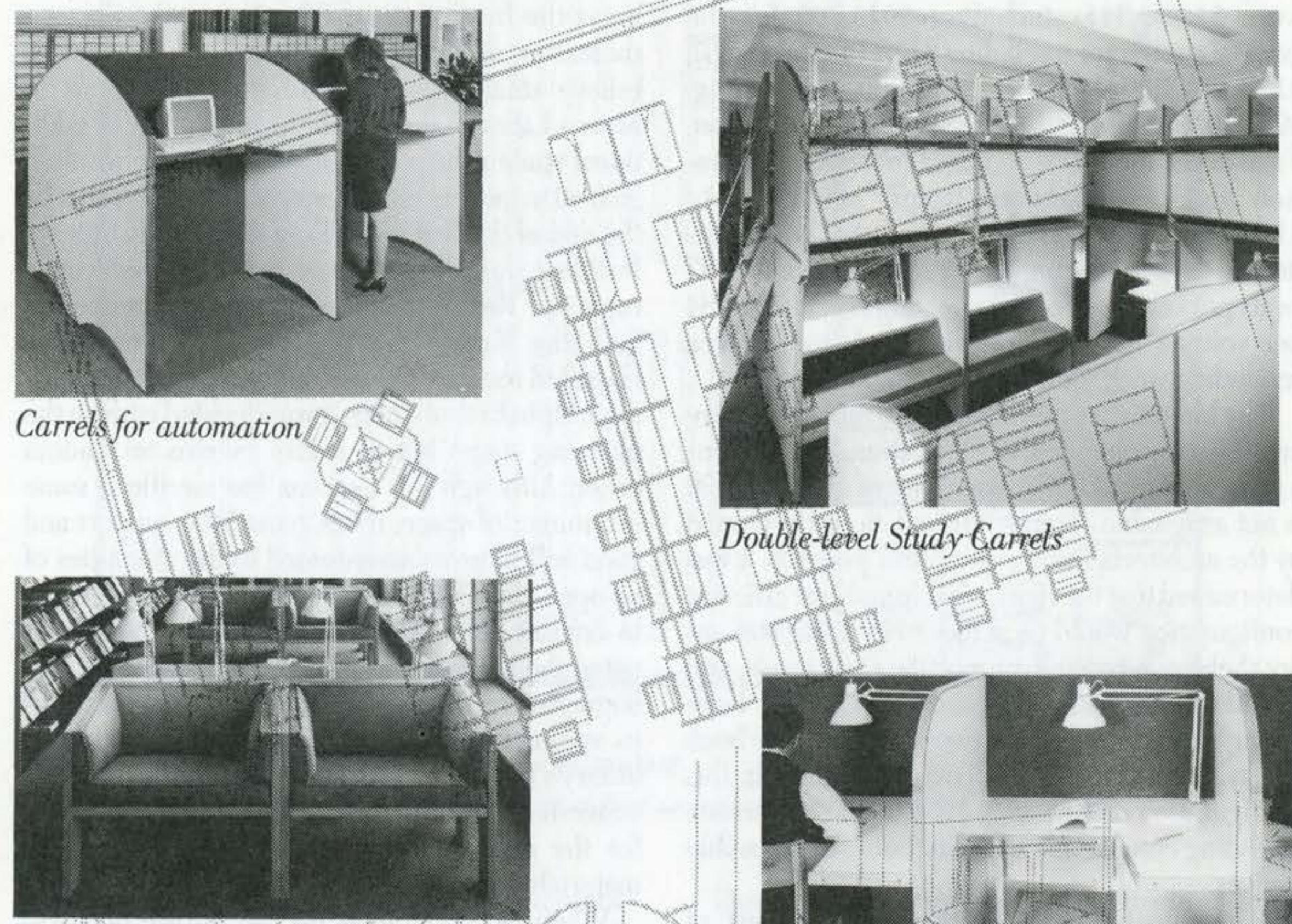

U) $\cup$,

Lounge Seating

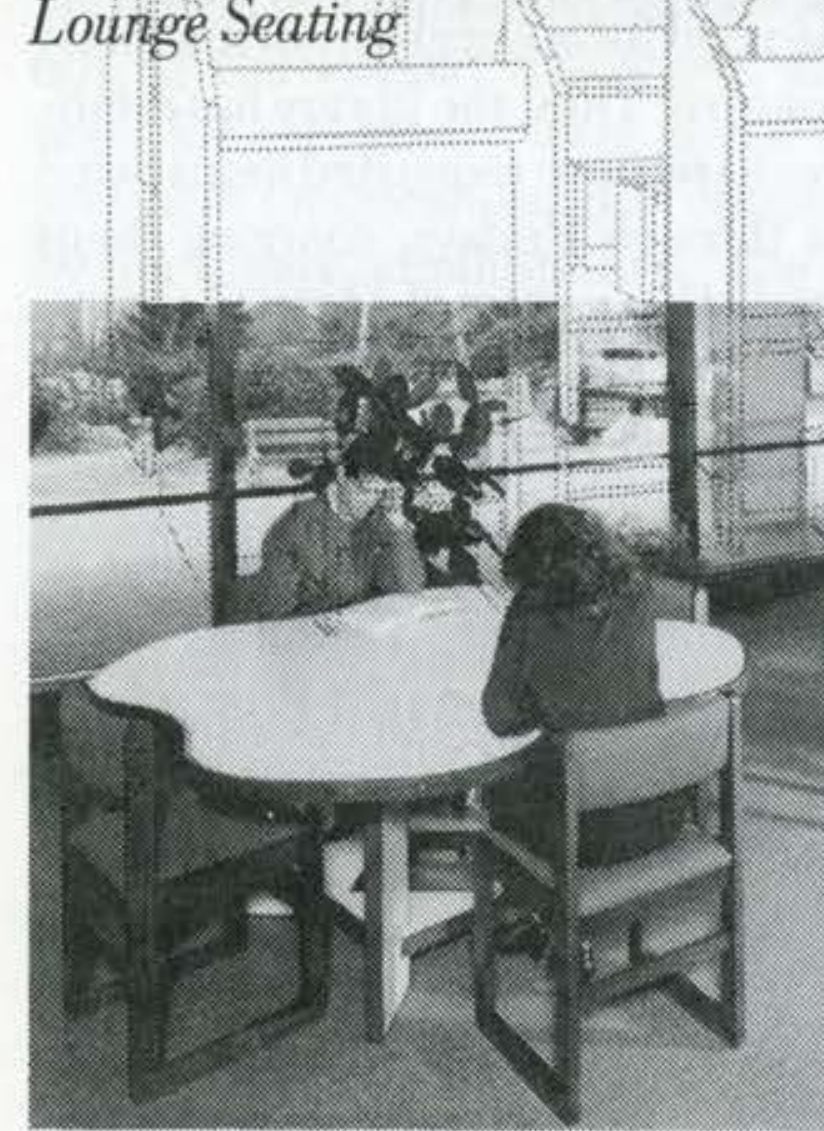

The Amoeba Table 
viewed after their first year of operation. Judging by the low request rate for items to be transferred back to the main library and modest circulation figures, the selection of older materials and items in little demand has been successful. Having achieved relief for the overcrowding of Morris Library, con- struction of the storage building has provided an interim solution to the need for additional stacks. Renewal of planning for a major addition to Morris Library, however, has recently been authorized, with hope that construction will be possible within the next three or four years.

\title{
The University of Crete Library
}

\author{
By Jane Kemp \\ Circulation Librarian \\ Luther College
}

\section{A visit to a Mediterranean academic library.}

\section{W}

hile preparing for a trip to Greece this past summer, I decided to do some homework about academic libraries that I could visit at the same time. Since my itinerary scheduled a week in Crete, a visit to an academic library on that island fitted most easily into my schedule.

My first step was to read about Greece in the ALA World Encyclopedia of Library and Information Services (ALA, 1986). Here I learned that the University of Crete is relatively new (organized in 1977) and has the only library in Greece completely arranged on the basis of LC classification. My second step was to focus on the University of Crete by reading about it in The World of Learning (Europa Publications, 1988). From here I discovered that the University is divided into two campuses, one in Rethimnon and the other in Iraklion. Since I would be visiting the latter for a longer period of time (the largest city in Crete and the site of Knossos), I narrowed my options to visiting the library on that campus.

From the Lion's Fountain in the center of Iraklion, bus No. 2 or 3 is routed past the University of Crete for the price of 50 drachmas (about 35 cents). Since this bus is usually packed with tourists on their way to Knossos (located at the terminus of the route), I was lucky to find a local, English-speaking student who could direct me to the university. Located at the top of a steep embankment, it cannot be seen from the street.

After arriving, I was disappointed to learn that the librarian, Janet Tavernaraki, was gone for the day. However, Prof. Flytzanis Nikos of the Physics Department and member of the library committee, was available to give me a walking tour of the library.

He reiterated what I had learned before coming to Crete, that the Faculties of Letters and Physical Sciences are located in two different towns, about one hour apart by car. The facility I visited in Iraklion housed the departments of physics, mathematics, computer science, medicine, chemistry and biology. Founded in 1979 (the other campus started in 1977), the Iraklion campus has an enrollment of 2,500-3,000 students each year. The school year is based on the semester model and runs from September through June.

The building housing the library also houses many of the other departments which compose the Iraklion campus. The present facilities are rapidly 